\title{
Use of fine aggregate matrix to analyze the rheological behavior of cold recycled materials
}

\author{
Andrea Graziani (iD) - Simone Raschia • Chiara Mignini (i) - Alan Carter (iD) \\ Daniel Perraton
}

Received: 27 March 2020/Accepted: 16 June 2020

(C) The Author(s) 2020, corrected publication 2021

\begin{abstract}
Nowadays, one of the main challenges to a wider application of cold recycling techniques is the lack of reliable information on the mechanical behavior of cold recycled materials (CRM). In this context, measurement and modelling of the complex modulus of CRM mixtures may give an important contribution to the design and analysis of pavements including cold recycled layers. In this study, we analyzed the rheological behavior of CRM mixtures produced using bitumen emulsion and cement through the study of their fine aggregate matrix (FAM). Starting from a fixed CRM mixture composition, we compared different FAM mortars, focusing on the effect of water and air content. Then, we selected a composition as representative of the FAM in the mixture and investigated the evolution of both materials during a fixed curing period. Next, we measured the complex modulus of the CRM mixture and FAM at two curing stages and applied a rheological model to simulate and compare their behavior. Results showed that the properties of CRM mixtures are comparable to those
\end{abstract}

A. Graziani $(\bowtie) \cdot$ C. Mignini

Department ICEA of Civil and Building Engineering, and Architecture, Polytechnic University of Marche, Via

Brecce Bianche, 60131 Ancona, Italy

e-mail: a.graziani@univpm.it

S. Raschia - A. Carter · D. Perraton

Construction Engineering Department, École de

Technologie Supérieure (ÉTS), 1100, Notre-Dame Street

West, Montréal, Canada of FAM mortars produced using all the binding agents (bitumen emulsion and cement) and a fraction of the voids contained in the mixture. Despite the huge difference in volumetric compositions, the FAM mortar controlled the curing and the thermo-rheological behavior of the CRM mixture, while the coarse reclaimed asphalt aggregate fraction and the voids mainly affected the asymptotic properties (equilibrium and glassy moduli) and the non-viscous dissipation component.

Keywords Cold recycled materials - Fine aggregate matrix $\cdot$ Mortar $\cdot$ Curing $\cdot$ Complex modulus $\cdot$ Thermorheological modeling

\section{Introduction}

Cold recycling of bituminous pavements has gained the interest of an increasing number of road agencies and contractors worldwide. On the one hand, this is due to the increasing emphasis that is placed on sustainability and reuse of end-of-life products like reclaimed asphalt (RA) [1-3]. On the other hand, field applications are showing that cold recycled materials (CRM) are an economically and structurally viable solution even for high traffic roadways [4-7].

In order to promote a wider application of CRM mixtures, a deeper knowledge of their mechanical behavior is critical. First, it must be recognized that 
CRM were developed and are applied following different composition concepts, leading to diverse mechanical behaviors $[8,9]$. CRM without any binder or treated only with Portland cement do exists but are not in the scope of this paper. In most cases, bitumen (bitumen emulsion or foamed bitumen) is the main binding agent and it is used in combination with Portland cement or chemical additives, such as lime. If Portland cement is used with dosages greater than about $1 \%$ with respect to the mass of aggregates, it has clear effect on the long-term properties of CRM mixtures, hence bitumen and cement shall be considered as co-binders [8, 10, 11]. In this case, the rheological behavior of CRM mixtures can be characterized by measuring the complex modulus $[12,13]$. However, compared to HMA, the complex modulus characterization of CRM mixtures must consider additional composition-related issues.

The first is that, due to water evaporation, emulsion breaking and cement hydration, CRM mixtures are subjected to a curing process and evolve from the "fresh" to the "hardened" state [14]. Therefore, if we are looking for stiffness values to be used in pavement design calculations, measurements must be carried out after a certain curing period. The second issue is that, CRM mixtures contain bitumen from emulsion or foam, as well as RA bitumen. The former is "fresh" and provides cohesion to the mixture, thanks to the emulsification of foaming processes. The former is aged, and, without heating, it is not able to blend with the fresh bitumen or to produce cohesion [15]. However, both the fresh and the aged bitumen are time- and temperature dependent materials and therefore they may affect the thermo-rheological behavior of the mixture [12, 16, 17].

The complex modulus of CRM mixtures can be measured using the same experimental procedures that were developed for HMA mixtures, and CRM mixtures can be considered thermo-rheologically simple materials, i.e. the time-temperature superposition principle can be applied to both the stiffness modulus (absolute value of the complex modulus) and the phase angle [8, 13]. In addition, the rheological models developed to simulate complex modulus of HMA, like the Huet-Sayegh model [18] or the 2S2P1D model [19] can also be used for CRM mixtures [12, 20, 21].

A further improvement to the rheological characterization of CRM mixtures is expected from the application of a multiscale approach and specifically from the study of their fine aggregate matrix (FAM). FAM materials were introduced to study the linear viscoelastic behavior, the fatigue and moisture damage properties of HMA mixtures [22-24]. FAM materials are essentially mortars, i.e. mixtures characterized by a nominal maximum aggregate size ranging between 1.18 and $4.76 \mathrm{~mm}$, whose composition should represent the FAM as it exists in the mixture [25-27]. FAM mortars have the same gradation of the fine fraction of the original mixture and are normally fabricated using all its bituminous binder, except the small fraction which is part of the thin film adhering to the surface of the coarse aggregate. The air voids content of FAM mortars is generally comprised between 0.5 and 0.7 of the total air voids of the mixture [27].

In the field of cold bituminous materials, which clearly includes CRM mixtures, mortars were considered either as model systems for investigating the properties of bitumen emulsions and their interaction with the cementitious binders [28, 29] or, alternatively, to investigate the properties of the CRM mixture itself [30].

The present research follows the second approach and our main objective is to compare the rheological behavior of CRM mixtures to that of mortars representing their FAM. The comparison is based on the measurement and modelling of the complex modulus. In the first part of the experimental study, starting from a fixed CRM mixture composition, we tested different mortar compositions obtained by removing the coarse aggregate and by changing the water and air content. In the second part, we selected a mortar composition to represent the FAM of the CRM mixture and investigated its curing behavior by monitoring the evolution of stiffness and water loss by evaporation. In the third part, we measured the complex modulus of both the CRM mixture and the selected FAM at two curing stages and finally we applied a new rheological model to analyze and compare their behavior.

\section{Materials and methods}

\subsection{Materials}

The CRM mixtures and FAM mortars tested in this study were produced in the laboratory by mixing RA 
aggregate, filler, Portland cement, bitumen emulsion and water, at ambient temperature.

The RA aggregate was sampled from a stockpile located in a cold recycling plant in Italy. Its nominal maximum aggregate size was $16 \mathrm{~mm}$ (Fig. 1), the particle density was $2482 \mathrm{~kg} / \mathrm{m}^{3}$, the water absorption was $1.0 \%$ and the bitumen content was $4.9 \%$ (by dry aggregate mass). In the laboratory, coarse and fine RA aggregate fractions were separated using the $2 \mathrm{~mm}$ sieve, their bitumen content was $3.3 \%$ and $8.3 \%$, respectively. The FAM mortar was produced using the fine fraction of RA aggregate, passing to the $2 \mathrm{~mm}$ sieve (Fig. 1). In this study RA aggregate is considered a "black rock", meaning that the aged asphalt is considered a part of the RA particles. The filler was a limestone powder with a particle density of $2650 \mathrm{~kg} /$ $\mathrm{m}^{3}$. The Portland cement was a GU type, with compressive strength at 28 days of $43.9 \mathrm{MPa}$ (ASTM C109). The bitumen emulsion was a commercial slowsetting type, designated as C 60 B 10 (EN 13108) specifically produced for cold recycling applications with cement (overstabilized emulsion), with a residual bitumen content of $60 \%$.

\subsection{Mixing and compaction procedures}

For mixing CRM mixtures and mortars, a strict control of the water content is necessary. For this reason, the
RA aggregate was dried at $40 \pm 2{ }^{\circ} \mathrm{C}$ until reaching constant mass and then a water amount corresponding to the absorption was added. The wet samples were stored in sealed plastic bags overnight, at room temperature, to allow a uniform moisture distribution and absorption. Mixing was carried out with a mechanical mixer and, during the process, additional water, cement, and bitumen emulsion were gradually added to the aggregate blend [31].

All the specimens were compacted with a gyratory compactor, adopting a constant pressure of $600 \mathrm{kPa}$, a gyration speed of $30 \mathrm{rpm}$ and an angle of inclination of $1.25^{\circ}$. Molds with a diameter of $100 \mathrm{~mm}$ and $150 \mathrm{~mm}$ were used for the compaction of mortars and mixtures, respectively.

\subsection{Composition of the CRM mixture}

The dry aggregate blend of the mixture was composed of $94 \%$ of RA aggregate and $6 \%$ of filler (by mass) and had a grading distribution close to the maximum density curve (Fig. 1). The dosage of bitumen emulsion (residual binder) and Portland cement were 5.0\% $(3.0 \%)$ and $1.5 \%$, respectively (by mass of the dry aggregate blend). Additional water was added to the mixture to help the homogeneous distribution of bitumen droplets and to improve workability and compactability. The total water content of the mixture,

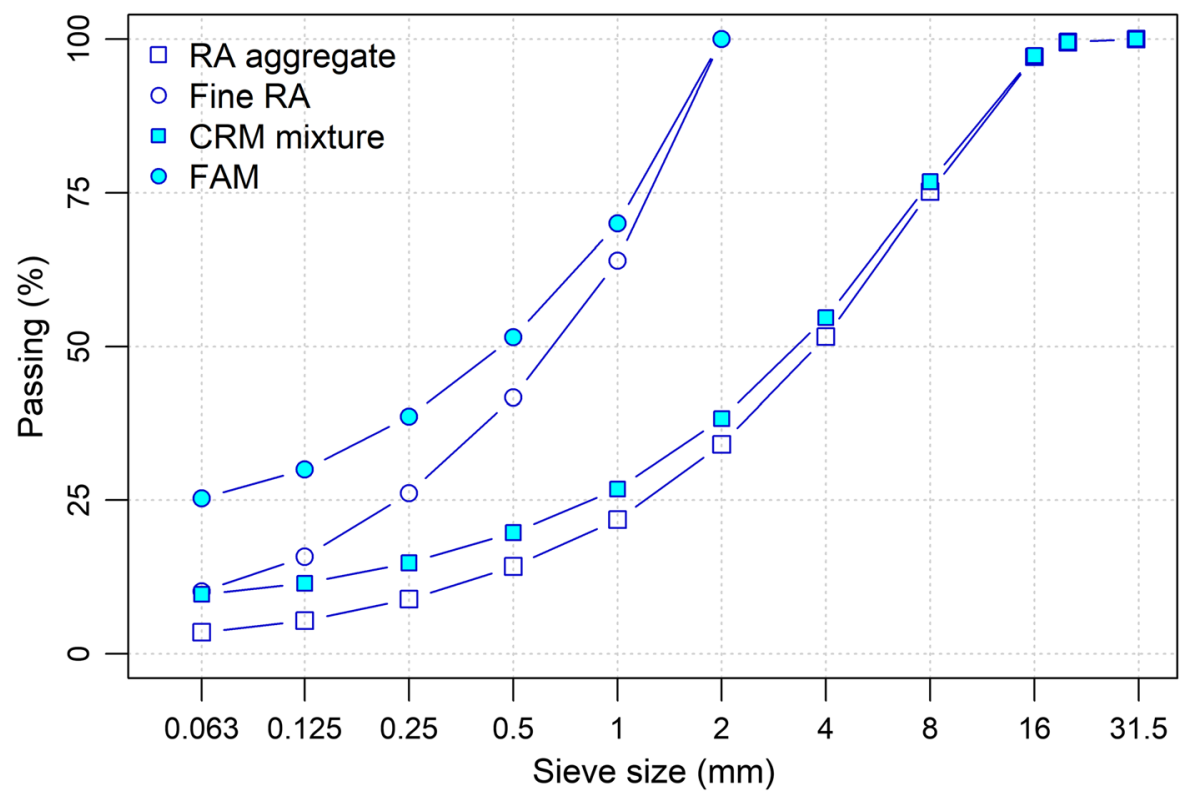

Fig. 1 Grading distribution of RA aggregate, CRM mixture and FAM mortar 
including additional water and emulsion water was $4.0 \%$ (by mass of the dry aggregate blend). This can be further subdivided into water absorbed by the RA aggregate (1.0\%) and intergranular water (3.0\%).

The volumetric composition of the freshly compacted mixture specimens is outlined in Fig. 2 and summarized in Table 1. To simplify the volumetric analysis, we consider the RA aggregate in saturated surface dry (SSD) condition, i.e. its volume is the bulk particle volume (including surface porosity), and its mass includes the absorbed water. We calculate the voids in the mixture $V_{\mathrm{m}}$ (volumetric fraction of the non-structural part) as follows:

$V_{\mathrm{m}}=\frac{v_{\mathrm{W}}+v_{\mathrm{A}}}{v}=\frac{v-\left(v_{\mathrm{S}}+v_{\mathrm{B}}\right)}{v}$

where $v$ is the total volume of the specimen (calculated using the mold diameter and the height measured by the gyratory compactor), $v_{\mathrm{W}}$ is the volume of the intergranular water (the volume of the absorbed water is included in the bulk volume of aggregates), and $v_{\mathrm{A}}$ is the volume of the air voids. The volume of voids $v_{\mathrm{W}}+$ $v_{\mathrm{A}}$ is obtained by subtracting the volume of the solids $v_{\mathrm{S}}$ (which includes the bulk volume of aggregates, filler and un-hydrated cement) and the volume of the residual bitumen from emulsion $v_{\mathrm{B}}$, from the total volume of the specimen. Equation 1 is correct only if during the compaction the material loss from the mold is negligible [31, 32]. For this reason, the mass of each specimen was measured immediately after the extraction from the mold and compared with the initial mass of the loose mixture cast in the mold. For all specimens, the mass loss during compaction was less than $0.3 \%$ and there was no observable leakage of water or fines.

In this study, we fixed the voids content of the mixture specimens at $V_{\mathrm{m}}=15 \%$. According to the mixture gravimetric composition given above, this comprised voids filled with intergranular water $\left(V_{\mathrm{W}}=v_{\mathrm{W}} / v=5.7 \%\right) \quad$ and $\quad$ air $\quad$ voids $\left(V_{\mathrm{A}}=v_{\mathrm{A}} / v=9.3 \%\right)$. As an example, Fig. 3 shows the compaction diagrams for the mixture and FAM mortar specimens that were tested in the second part of the experimental study (Sect. 3.2). The slope ( $k$ ) of the compaction curve (voids $V \mathrm{~s} \log N$ ) is reported in the plot and can be used as a numerical indicator of the compactability [33]. For the mixture specimens, the selected voids level $\left(V_{\mathrm{m}}=15.0 \%\right)$ was obtained after about 30 gyrations and the compactability $(k=8.66)$ was in agreement with previous studies [34, 35]. For the FAM mortar specimens, the selected voids level $\left(V_{\mathrm{m}}=14.8 \%\right.$, Sect. 2.4) was obtained after about 20 gyrations, and the compactability was lower $(k=6.59)$ with respect to mixtures.

\subsection{Composition of the FAM mortar}

To obtain the volumetric composition of the FAM mortar, starting from the given mixture composition, first we removed the volume of the coarse aggregate (in SSD condition). We included in the FAM a fraction of the mixture water (at least the emulsion water) and a fraction of the mixture air voids [30]. The remaining fraction of water and air was considered as an independent voids phase. As a result, we considered the mixture as a three-phase composite (Fig. 2):
Mixture
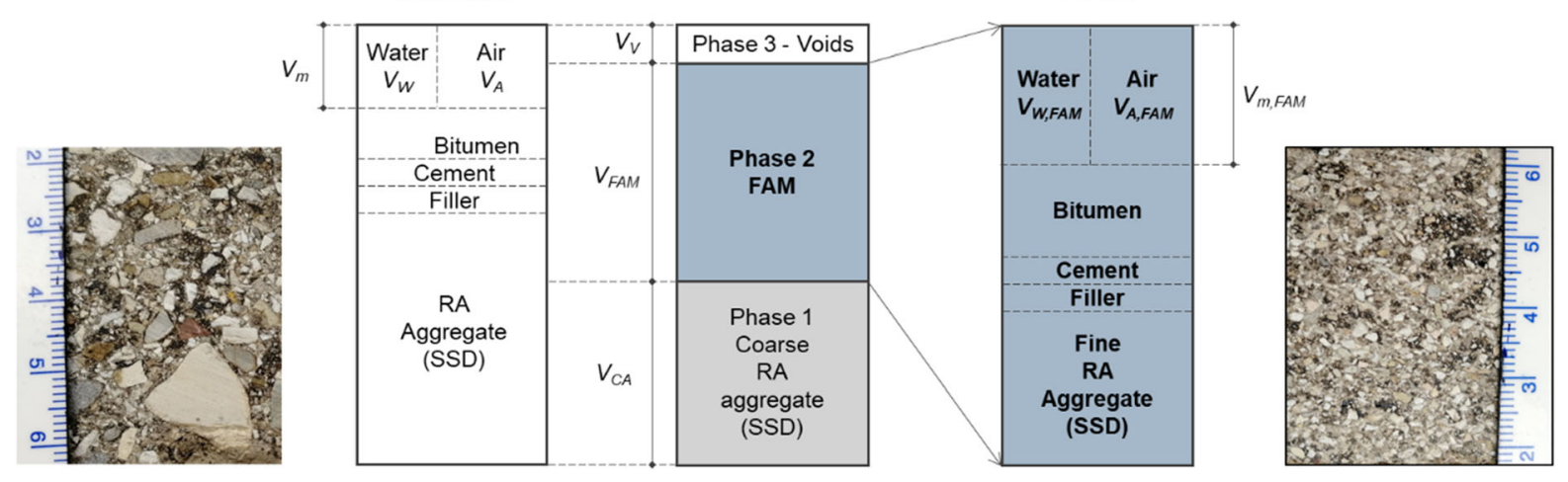

FAM

Fig. 2 Volumetric composition of CRM mixture and FAM mortar

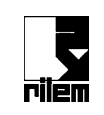


Table 1 Volumetric composition of mixture and mortars with respect to the total volume of each composite and number of gyrations needed for the compaction

\begin{tabular}{llllllllll}
\hline Component & Mixture & \multicolumn{2}{l}{ Mortars } & & & & \\
\cline { 3 - 9 } & & $(\%)$ & $\begin{array}{l}\text { REF } \\
(\%)\end{array}$ & $\begin{array}{l}A \\
(\%)\end{array}$ & $\begin{array}{l}B \\
(\%)\end{array}$ & $\begin{array}{l}C \\
(\%)\end{array}$ & $\begin{array}{l}D \\
(\%)\end{array}$ & $\begin{array}{l}E \\
(\%)\end{array}$ & $\begin{array}{l}F \\
(\%)\end{array}$ \\
\hline RA 2/20 & 49.0 & & & & & & & \\
RA 0/2 & 25.3 & 49.7 & 60.0 & 60.6 & 59.4 & 61.7 & 59.7 & 57.9 \\
Filler & 4.0 & 7.9 & 9.6 & 9.7 & 9.4 & 9.4 & 9.8 & 9.6 \\
Cement & 1.0 & 1.9 & 2.3 & 2.3 & 2.2 & 2.3 & 2.3 & 2.2 \\
Bitumen & 5.7 & 11.1 & 13.4 & 13.5 & 13.2 & 13.7 & 13.4 & 12.9 \\
Intergranular water & 5.7 & 11.2 & 13.6 & 12.3 & 12.1 & 11.3 & 11.1 & 10.7 \\
Air & 9.3 & 18.2 & 1.1 & 1.6 & 3.7 & 1.6 & 3.7 & 6.7 \\
Total & 100.0 & 100.0 & 100.0 & 100.0 & 100.0 & 100.0 & 100.0 & 100.0 \\
Gravimetric water dosage & 4.0 & 9.0 & 9.0 & 8.2 & 8.2 & 7.5 & 7.5 & 7.5 \\
$n^{\circ}$ gyrations & 26 & $*$ & 8 & 12 & 5 & 27 & 8 & 3 \\
\hline
\end{tabular}

*REF composition was impossible to compact

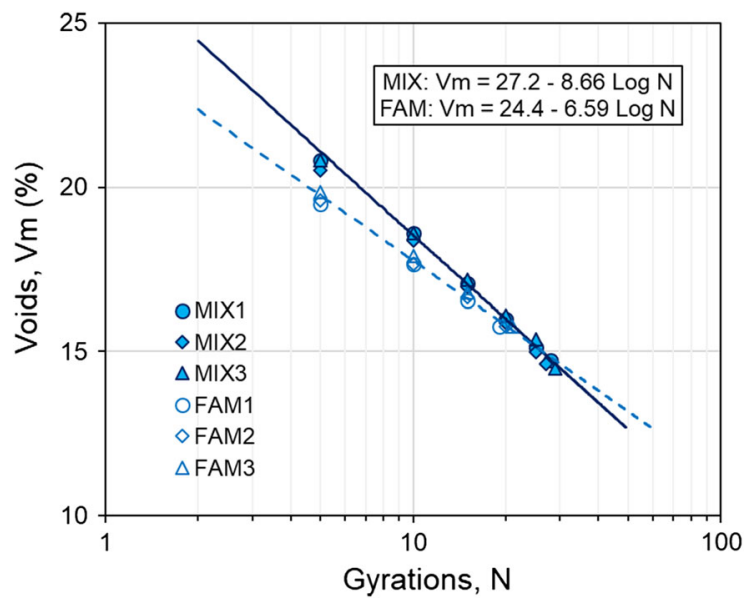

Fig. 3 Compaction curves for the specimens tested in the second part of the experimental study

1. The coarse aggregate, in SSD condition $\left(V_{\mathrm{CA}}\right)$.

2. The FAM ( $\left.V_{\mathrm{FAM}}\right)$, including the fine aggregate (passing to the $2 \mathrm{~mm}$ sieve), the filler, the residual bitumen from the emulsion, the Portland cement and a fraction of the mixture's intergranular voids, which are filled partly with water and partly air.

3. The fraction of voids not included in the FAM $\left(V_{\mathrm{V}}\right)$.

We can consider the FAM mortar as the binding matrix of the mixture, because it contains all the binders (bitumen and Portland cement) and the coarse aggregate as particle inclusions.

As regards the voids, separating the fraction that could be considered part of the FAM from the fraction that could be considered as an independent phase in the mixture required some judgement. For example, we could assume that those voids with characteristic size smaller than about $2 \mathrm{~mm}$ could be part of the FAM, whereas larger ones could be considered as an independent phase. However, this posed the additional issue of measuring the size distribution of the voids, which was beyond the scope of the research. We decided to investigate this issue by preparing and testing seven mortars with different voids content $V_{\mathrm{m}, \mathrm{FAM}}$, i.e. with different $V_{\mathrm{W}, \mathrm{FAM}}$ and $V_{\mathrm{A}, \mathrm{FAM}}$ (Fig. 2). The mortar compositions were obtained applying the principles described above and thus were characterized by the same grading distribution (Fig. 1), gravimetric dosage of emulsion (13.5\%) and Portland cement $(4.1 \%)$.

The volumetric composition of mixture and mortars is summarized in Table 1 . The reference (REF) mortar was obtained by removing only the SSD coarse RA aggregate from the mixture and contained all the mixture's voids (water and air). Therefore, it would correspond to a mixture without an independent voids phase $\left(V_{\mathrm{V}}=0\right)$. This mortar had a volume of voids $V_{\mathrm{m}, \mathrm{FAM}}=V_{\mathrm{W}, \mathrm{FAM}}+V_{\mathrm{A}, \mathrm{FAM}}=11.2 \%+18.2 \%=$ $29.4 \%$, while its calculated gravimetric water content was $9.0 \%$. We mixed this mortar composition in the laboratory, but we were not able to compact a specimen because the uncompacted mortar cast in the gyratory mold had less than $24.9 \%$ of voids. In other words, the volume of voids included in the mixture $\left(V_{\mathrm{m}}=15.0 \%\right)$ was too high to fit inside the FAM phase and therefore the multiphase mixture model (Fig. 2) must include the independent voids phase. 
The mortar A was prepared with the same gravimetric water dosage of the REF mortar but was compacted until reaching the minimum fraction of air voids of $1.1 \%$. We tried to compact this mortar until reaching zero air voids (saturation condition), but it was impossible because leakage of water started from the bottom and the top of the mold and the compaction had to be stopped to preserve the original composition, as explained in Sect. 2.3 for the mixtures. In other words, a minimum amount of entrapped air voids must be included in the mortar.

For compositions $\mathrm{B}$ and $\mathrm{C}$, we reduced the gravimetric water dosage to $8.2 \%$, while for compositions $\mathrm{D}, \mathrm{E}$ and $\mathrm{F}$ the water dosage was reduced to $7.5 \%$. A further reduction was not possible because the mortar became too dry, not homogeneous and almost impossible to compact. Like mortar A, mortars B and D were compacted until reaching the minimum level of entrapped air voids (in this case 1.6\%), without leakage of water from the mold.

Figure 4 describes the volumetric properties of all the tested mortars: the $x$-axis is the fraction of air voids in the mortar to the air voids in the mixture $\left(v_{\mathrm{A}, \mathrm{FAM}} / v_{\mathrm{A}}\right)$, while the $y$-axis is the volumetric fraction of water in the mortar to total water in the mixture $\left(v_{\mathrm{w}, \mathrm{FAM}} / v_{\mathrm{W}}\right)$. The dashed lines drawn in the plot describe the values $V_{\mathrm{m}, \mathrm{FAM}}=$ constant. The upperright corner of the plot represents the REF composition $\left(v_{\mathrm{A}, \mathrm{FAM}} / v_{\mathrm{A}}=v_{\mathrm{w}, \mathrm{FAM}} / v_{\mathrm{W}}=1\right)$. Since the mortars

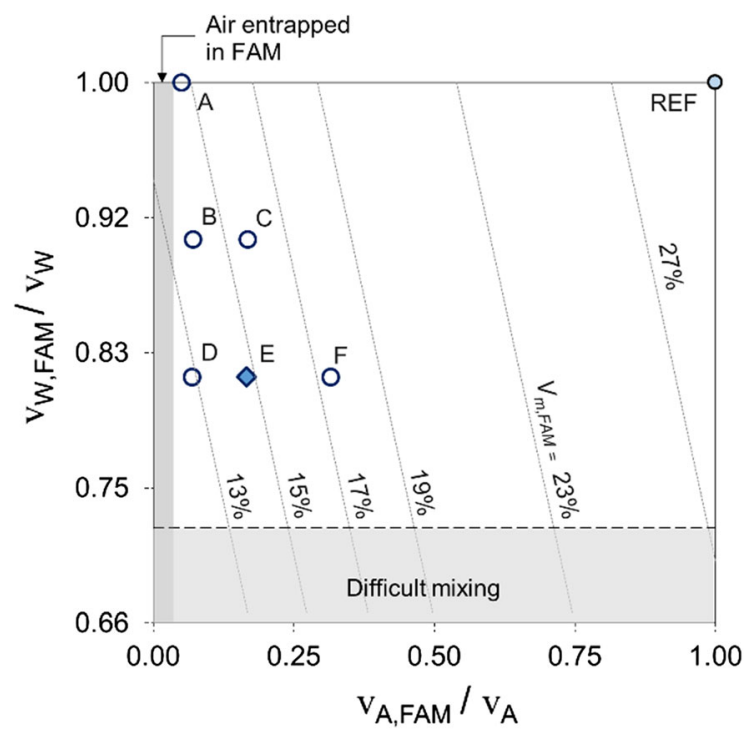

Fig. 4 Volumetric properties of the tested mortars were produced using all the bitumen emulsion of the mixture, the minimum value on the $y$-axis corresponds to the water content of the emulsion (for our mixture this was 0.66). Moreover, in Fig. 4 we outlined two areas along the bottom and left margins of the plot, which qualitatively indicate configurations that were impossible to mix or compact in the laboratory, starting from the mixture composition given above.

\subsection{Testing procedures}

In the first part of the experimental study, to evaluate the effect of the voids on the mortar composition, we measured the Indirect Tensile Strength (ITS) of the materials listed in Table 1. Two replicate specimens were tested for each material composition. The test was carried out at $25^{\circ} \mathrm{C}$, after 1 day of curing at the same temperature [30]. Following the standard EN 12697-23, we applied a constant rate of deformation $(50 \pm 2 \mathrm{~mm} / \mathrm{min}$ ) until failure and the ITS was calculated following Eq. 2.

$\mathrm{ITS}=\frac{2 F_{\mathrm{MAX}}}{\pi D H}$

where $F_{\mathrm{MAX}}$ is the maximum compressive force sustained by the specimen, $H$ and $D$ are the specimen height and diameter, respectively.

In the second part of the study, we selected a specific FAM mortar composition $(E)$ and compared its curing behavior to the curing behavior of the mixture. We produced three replicate specimens for both the mixture and the FAM, having $100 \mathrm{~mm}$ diameter and $67.4 \mathrm{~mm}$ and $64.7 \mathrm{~mm}$ height, respectively. Curing started immediately after compaction, and consisted of a first phase of 14 days at $25{ }^{\circ} \mathrm{C}$ followed by a second phase of 14 days at $40{ }^{\circ} \mathrm{C}$ [36]. During the curing phases, we measured the water loss (WL) due to evaporation (Eq. 3) after 6 h, 1, 3, 7, 14, 15, 17, 21 and 28 days.

$\mathrm{WL}=\frac{M_{0}-M_{i}}{W_{\mathrm{TOT}}} \cdot 100$

where $M_{0}$ is the specimen mass right after compaction, $M_{i}$ is the specimen mass after $i$ curing days and $W_{\text {TOT }}$ is the total mass of water in the specimen.

On the same specimens, starting from the third day of curing, we also measured the Indirect Tensile Stiffness Modulus (ITSM) (Eq. 4) according to the standard EN 12697-26. The test measured the average 
stiffness at $25{ }^{\circ} \mathrm{C}$ after the application of $10+5$ pulse loads (conditioning + test pulses) with a rise time of $124 \pm 4 \mathrm{~ms}$ and a target horizontal strain of $3 \times 10^{-6} \mathrm{~mm} / \mathrm{mm}$.

$\operatorname{ITSM}=\frac{F_{\max }(v+0.27)}{H d_{\max }} \cdot 100$

where $F_{\max }$ is the maximum value of the pulse load, $d_{\max }$ is the corresponding maximum value of the horizontal deformation, $v$ is the Poisson's ratio (assumed equal to 0.35) and $H$ is the specimen height.

In the third part of the study, we measured the complex modulus $E^{*}(\omega)$ (Eq. 5) of the mixture and the selected FAM mortar composition at the end of the two curing stages, i.e. after 14 days at $25^{\circ} \mathrm{C}$ and after the additional 14 days at $40{ }^{\circ} \mathrm{C}$. Two specimens of each material were prepared with the gyratory compactor, in a $100 \mathrm{~mm}$ mold, to the final height of $130 \mathrm{~mm}$ and then cored to the diameter $75 \mathrm{~mm}$ at the end of curing. The test was carried out using an AMPT PRO system where the axial stress was measured with a load cell, while the axial strain was measured in the middle part of the specimen (measuring base of $70 \mathrm{~mm}$ ) using three LVDT, placed $120^{\circ}$ apart. A haversine compression loading was applied to obtain a target strain amplitude of $30 \cdot 10^{-6} \mathrm{~mm} / \mathrm{mm}$. The testing temperatures were $0,10,20,30$ and $40^{\circ} \mathrm{C}$, the testing frequencies were $0.1,0.5,1,5$ and $10 \mathrm{~Hz}$ and 20 loading cycles were applied at each frequency.

$E^{*}(\omega)=E_{0}(\omega) \cdot \exp [\mathrm{j} \delta(\omega)]$

where $\mathrm{j}$ is the imaginary unit, $\omega=2 \pi f$ is the angular frequency ( $f$ is the testing frequency in $\mathrm{Hz}), \delta(\omega)$ is the phase angle and $E_{0}(\omega)$ is the stiffness modulus (Eq. 6):

$E_{0}=\frac{\sigma_{0}}{\epsilon_{0}}$

where $\sigma_{0}$ and $\epsilon_{0}$ are the steady-state sinusoidal amplitudes of the measured stress and strain signals.

\section{Results and analysis}

\subsection{Mortar composition}

Figure 5 shows the ratio of the ITS of the six FAM mortar compositions $\left(\right.$ ITS $_{\mathrm{FAM}}$ ) to the ITS of the mixture $\left(\operatorname{ITS}_{\mathrm{MIX}}=0.142 \mathrm{MPa}\right)$. This ratio is plotted

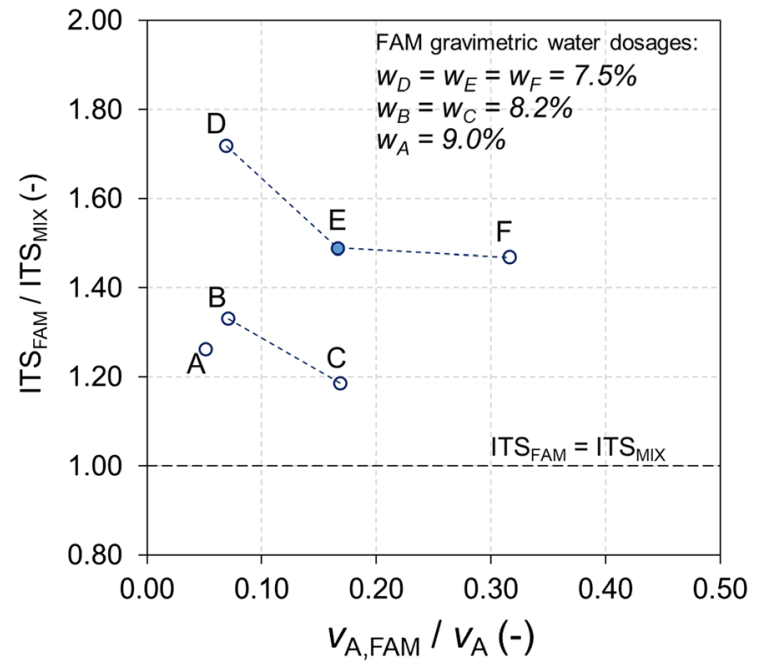

Fig. 5 Ratio between ITS of FAM and mixtures (after one day of curing at $25^{\circ} \mathrm{C}$ ) as a function of the ratio between air voids contents of FAM and mixture

as a function of the air voids fraction in the mortar, $v_{\mathrm{A}, \mathrm{FAM}} / v_{\mathrm{A}}$, measured after compaction (the same used in Fig. 4). The ITS of the FAM mortars increased when the water dosage decreased and, for each water dosage, it increased when the air content was reduced. Moreover, all the tested FAM mortar compositions had an ITS higher than the mixture. This is because only a small fraction of the air content of the mixture could be included in the mortars (less than $32 \%$ ), while the remaining fraction should be considered as part of the mixture, within the independent voids fraction (Fig. 2, Phase 3).

All the mortar volumetric compositions (A to F) are potentially representative of the FAM properties within the mixture. However, to analyze the effect of curing and to evaluate the rheological behavior, we chose composition E. We considered compositions A, $\mathrm{B}$ and D not representative of the FAM within the mixture because they were characterized by a very low air voids content $\left(v_{\mathrm{A}, \mathrm{FAM}} / v_{\mathrm{A}}<0.1\right)$, whereas the mixture had a relatively high air voids content. We preferred composition $\mathrm{E}$ over compositions $\mathrm{C}$ and $\mathrm{F}$ because it required a higher compaction energy (number of gyrations given in Table 2), closer to the energy required by the mixture. Adopting mortar E to represent the FAM, the volumetric composition of the mixture (Fig. 2) would be as follows:

- Phase 1 coarse aggregate, $V_{\mathrm{CA}}=49.0 \%$. 
Table 2 Parameters of the modified HS and WLF model parameters $\left(T_{\text {ref }}\right.$ $=20{ }^{\circ} \mathrm{C}$ )

\begin{tabular}{llrlllllll}
\hline Material & $\begin{array}{l}E_{\mathrm{e}} \\
(\mathrm{MPa})\end{array}$ & $\begin{array}{l}E_{\mathrm{g}} \\
(\mathrm{MPa})\end{array}$ & $k$ & $h$ & $d$ & $\log \tau$ & \multicolumn{1}{l}{$\begin{array}{l}\delta_{0} \\
\left({ }^{\circ}\right)\end{array}$} & \begin{tabular}{l}
$C_{1}$ \\
\multicolumn{1}{c}{$\begin{array}{l}C_{2} \\
\left({ }^{\circ} \mathrm{C}\right)\end{array}$}
\end{tabular} \\
\hline FAM1-14 & 295 & 9552 & 0.122 & 0.314 & 1.634 & -1.823 & 0.337 & 14.4 & 123.8 \\
FAM2-14 & 518 & 9533 & 0.122 & 0.314 & 1.634 & -1.659 & 0.793 & & \\
FAM1-28 & 484 & 10,766 & 0.122 & 0.314 & 2.000 & -1.228 & 0.391 & 56.6 & 446.4 \\
FAM2-28 & 561 & 11,125 & 0.122 & 0.314 & 2.000 & -1.021 & 0.366 & & \\
MIX1-14 & 269 & 9224 & 0.122 & 0.314 & 1.634 & -1.478 & 1.758 & 12.7 & 107.9 \\
MIX2-14 & 217 & 9931 & 0.122 & 0.314 & 1.634 & -1.147 & 1.789 & & \\
MIX1-28 & 196 & 9369 & 0.122 & 0.314 & 2.000 & -0.371 & 1.530 & 26.7 & 192.5 \\
MIX2-28 & 240 & 11246 & 0.122 & 0.314 & 2.000 & 0.313 & 0.945 & & \\
\hline
\end{tabular}

- Phase 2 FAM, $V_{\mathrm{FAM}}=42.2 \%$ (detailed composition is given in Table 1).

- Phase 3 independent voids: $8.8 \%$ (1.1\% water, $7.7 \%$ air).

\subsection{Evolutive behavior of mixture and FAM}

Figure 6 shows the relationship between the evolution of $W L$ of the FAM (composition E) and the mixture, from $6 \mathrm{~h}$ to 28 days of curing. We observe that $W L_{\mathrm{MIX}}$ was always higher than $W L_{\mathrm{FAM}}$ and, except the first few hours, the rate of water loss for mixture and FAM was practically identical. The same result was obtained in a previous study on similar materials (see Figure 6 in [30]).

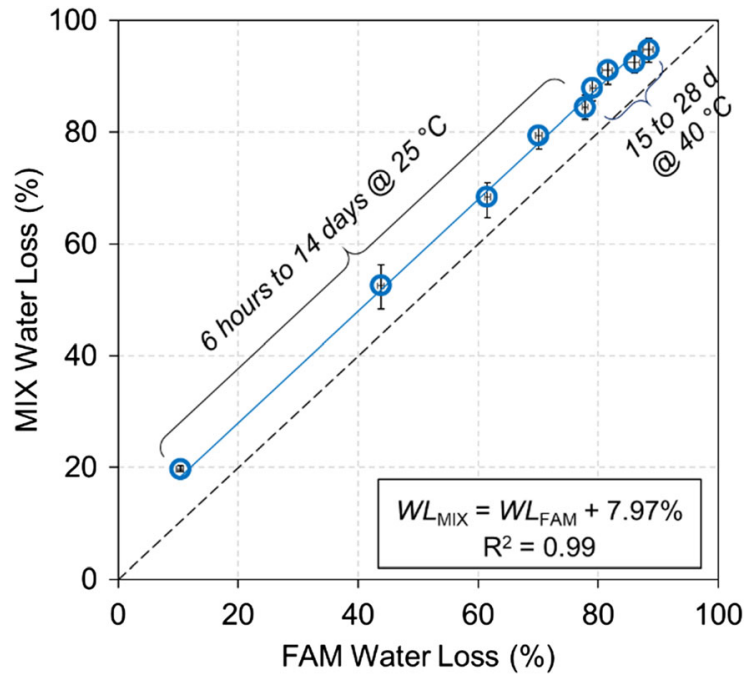

Fig. 6 Evolution of water loss of the mixture and the FAM (composition E) during the curing period
Water evaporation from porous media is often described as a two-stage process. In the first stage, the rate of water loss per unit surface is nearly constant and close to the evaporation rate from a free water surface. In the second stage, evaporation is characterized by a falling rate and is controlled by the diffusion of vapor through the pores of the medium [37, 38]. The results of this study, and the results presented in [30], clearly indicate that after the first few hours of curing, the evaporation rate decreased for all specimens, thus we were in the diffusion stage. Moreover, since the water loss from the mixture and the FAM mortar was strictly related, the pore structure of the two materials could be similar. However, this hypothesis needs further confirmation that can be obtained only with an experimental characterization of the pore structure of both materials.

Figure 7 shows the relationship between the ITSM of mixture and FAM, from 3 to 28 days of curing. At short curing times, the mixture was stiffer than the FAM mortar. This indicated that the reinforcing effect of the CA particles $\left(V_{\mathrm{CA}}\right)$ prevailed on the weakening effect of the independent voids $\left(V_{\mathrm{V}}\right)$. Afterwards, the difference with FAM reduced and, after about 18 days, the FAM became stiffer than the mixture, highlighting the effect of voids.

To model the relation between the ITSM of mixture and FAM, among the various equations proposed in the literature for particulate composites [39], we chose a slightly modified version of the Hirsch model (Eq. 7), that was originally developed for cement concrete and later applied to HMA [40].

$$
\begin{aligned}
E_{\mathrm{MIX}}= & x\left(E_{\mathrm{CA}} V_{\mathrm{CA}}+E_{\mathrm{FAM}} V_{\mathrm{FAM}}\right) \\
& +(1-x)\left(\frac{V_{\mathrm{CA}}}{E_{\mathrm{CA}}}+\frac{V_{\mathrm{FAM}}}{E_{\mathrm{FAM}}}\right)^{-1}
\end{aligned}
$$




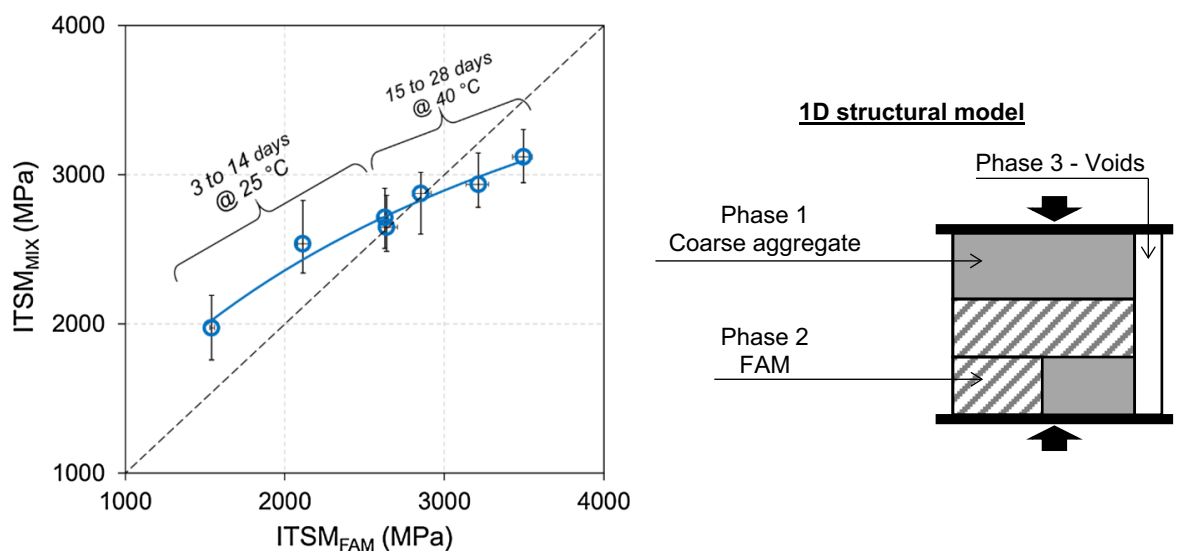

Fig. 7 Relationship between the evolution of ITSM of the mixture and the FAM (composition E) during the curing period and structural model used for regression (Eq. 7)

where $x$ and $(1-x)$ are the relative proportions of material conforming to series and parallel arrangement, respectively, $V_{\mathrm{CA}}, V_{\mathrm{FAM}}$ are the volumetric fractions of coarse aggregate and FAM, respectively, $E_{\mathrm{MIX}}, E_{\mathrm{FAM}}$ and $E_{\mathrm{CA}}$ are the moduli of mixture, FAM and coarse aggregate fraction, respectively.

According to the volumetric composition of mortar E, we used $V_{\mathrm{CA}}=0.490, V_{\mathrm{FAM}}=0.422$, and thus we explicitly considered the independent voids phase in parallel arrangement with the structural part of the material (CA and FAM), as outlined in Fig. 7. Using least squares error minimization, we estimated $E_{\mathrm{CA}}=$ $2912 \mathrm{MPa}$ and $x=0.108$. The resulting model is plotted in Fig. 7 and gives an excellent fitting of the experimental data. We recall that parallel arrangement implies equality of strain and thus perfect bonding between the FAM and the CA particles, on the other hand, series arrangement implies equality of stress which can be related to poor bonding [39]. The model fitting results suggests that series arrangement prevailed $(89.2 \%)$, suggesting that in the mixture the bonding between CA particles (RA particles retained on the $2 \mathrm{~mm}$ sieve) and FAM was rather poor.

\subsection{Complex modulus results}

Figure 8 shows the measured data of stiffness modulus and phase angle in the Black diagram for CRM mixture and FAM (composition E), at 14 and 28 days of curing. Despite the large differences in composition (Table 1), the rheological behavior of the mixture and the FAM was similar. The highest values of stiffness modulus (about $7000 \mathrm{MPa}$ ) and the lowest values of phase angle (about $5^{\circ}$ ) were measured at the lowest testing temperature $\left(0{ }^{\circ} \mathrm{C}\right)$ and highest frequency $(10 \mathrm{~Hz})$. Increasing the temperature and decreasing the frequency led to the decrease of stiffness modulus until reaching the minimum (about $700 \mathrm{MPa}$ ) at the highest temperature $\left(40{ }^{\circ} \mathrm{C}\right)$ and lowest frequency $(0.1 \mathrm{~Hz})$. Concurrently, the phase angle increased reaching a maximum (about $19^{\circ}$ for mixtures and $15^{\circ}$ for FAM) at $40{ }^{\circ} \mathrm{C}$, when the stiffness modulus was about $1500 \mathrm{MPa}$.

This behavior clearly resembles the behavior of HMA, but for CRM mixtures and FAM it is due to the frequency and temperature susceptibility of the two distinct bituminous components: the residual bitumen from the emulsion and the RA bitumen. Moreover, cementitious bonds limited the variability of the stiffness modulus values within about one order of magnitude (700-7000 $\mathrm{MPa}$ ) and the maximum phase angle to values less $20^{\circ}$. Similar trends can be observed in [12, 13, 41].

In Fig. 8 we also outlined the effect of curing, which can be better observed in Fig. 9, where we directly compared the stiffness modulus and phase angle results (same temperature and same frequency) after 14 and 28 days. Throughout the temperature and frequency range, $E_{0}$ increased between 15 and $20 \%$, in agreement with the ITSM measurements shown in Fig. 7. Concurrently, there was a phase angle decrease of about $1^{\circ}$ to $4^{\circ}$. Overall, the $E^{*}$ variation followed about the same pattern as for temperature decrease and frequency increase [14] which explains why the effect of curing is not clearly visible in Fig. 8. 
(a)

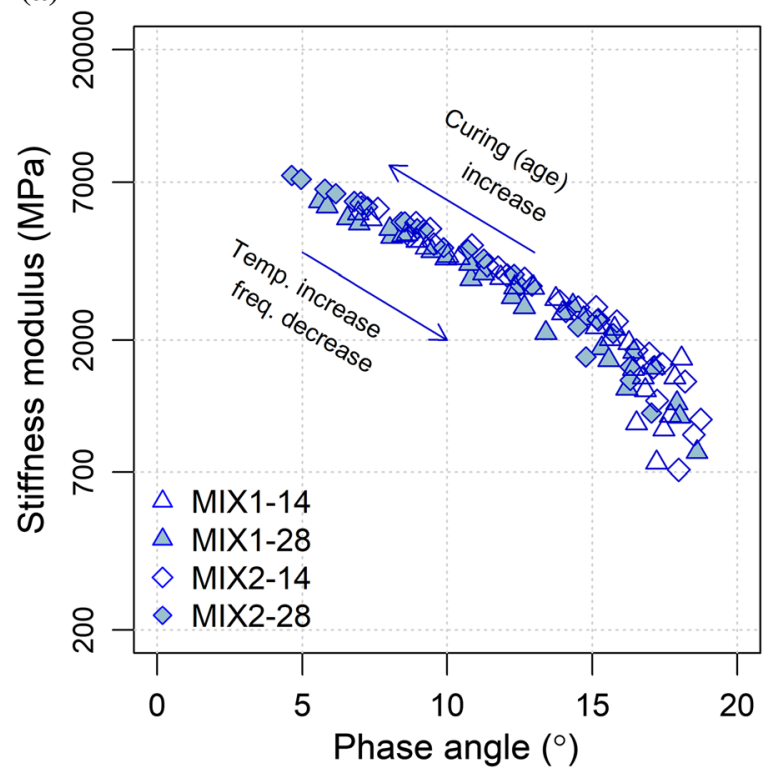

(b)

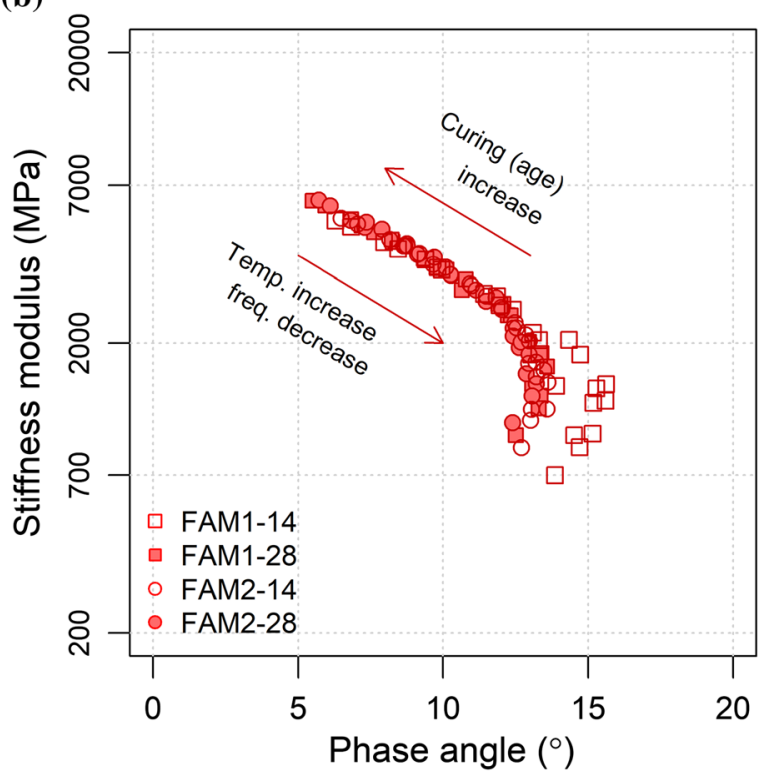

Fig. 8 Stiffness modulus and phase angle data at 14 and 28 days of curing plotted in the Black diagram, a mixture (two specimens), b FAM composition $\mathrm{E}$ (two specimens)
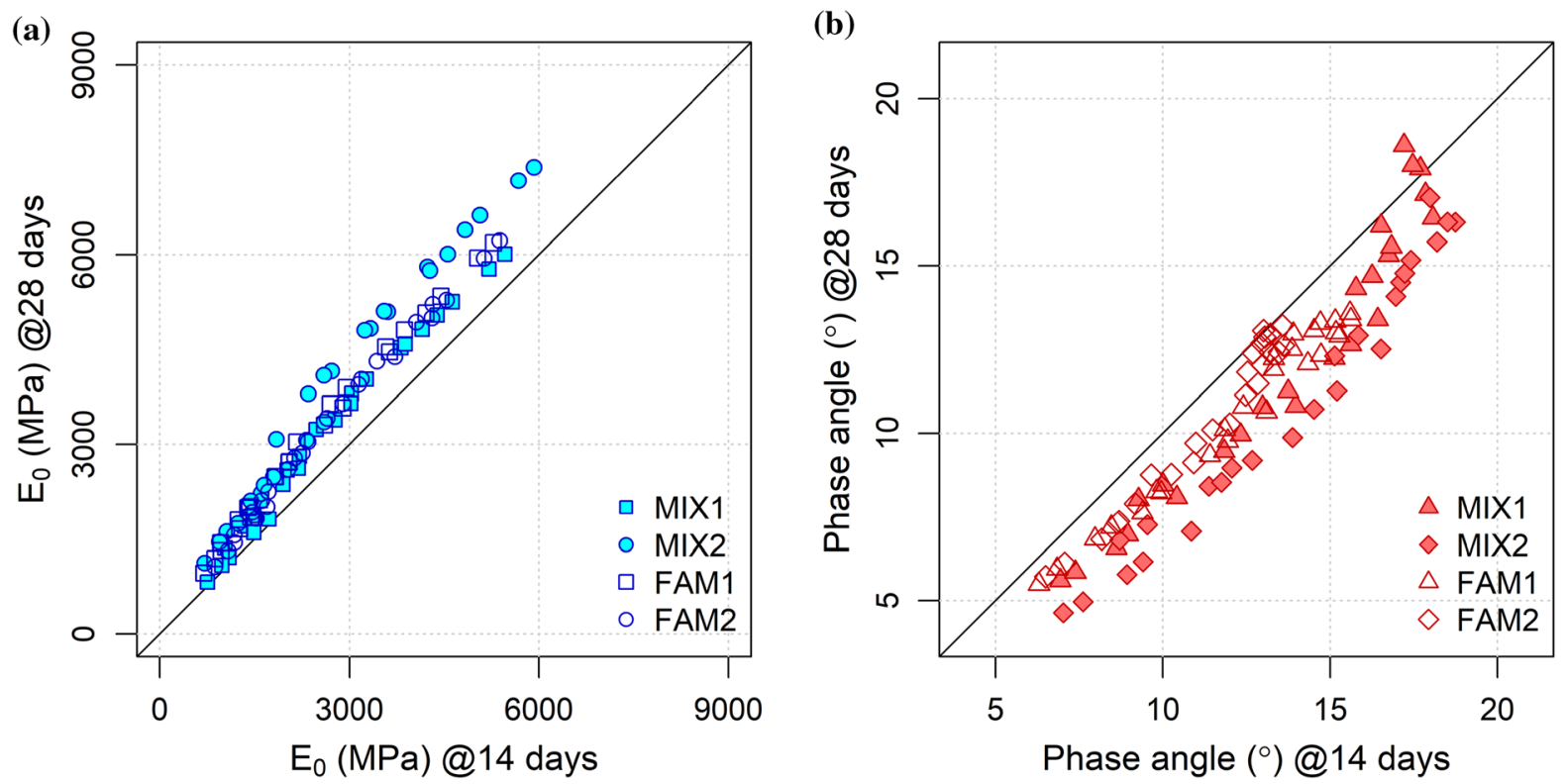

Fig. 9 Effect of curing on the rheological properties: a stiffness modulus; $\mathbf{b}$ phase angle

\subsection{Thermo-rheological modeling}

Figure 8 shows that, for all the specimens and curing conditions, the $\left(E_{0}, \delta\right)$ pairs describe a single curve in the Black diagram. This confirms the validity of the time-temperature superposition principle (variations of temperature and frequency have the same effect on $\left.E^{*}\right)$ and thus allows the creation of master curves.

The master curves of the stiffness modulus (Fig. 10a) were obtained by selecting the reference temperature $T_{\text {ref }}=20^{\circ} \mathrm{C}$ and shifting the data 

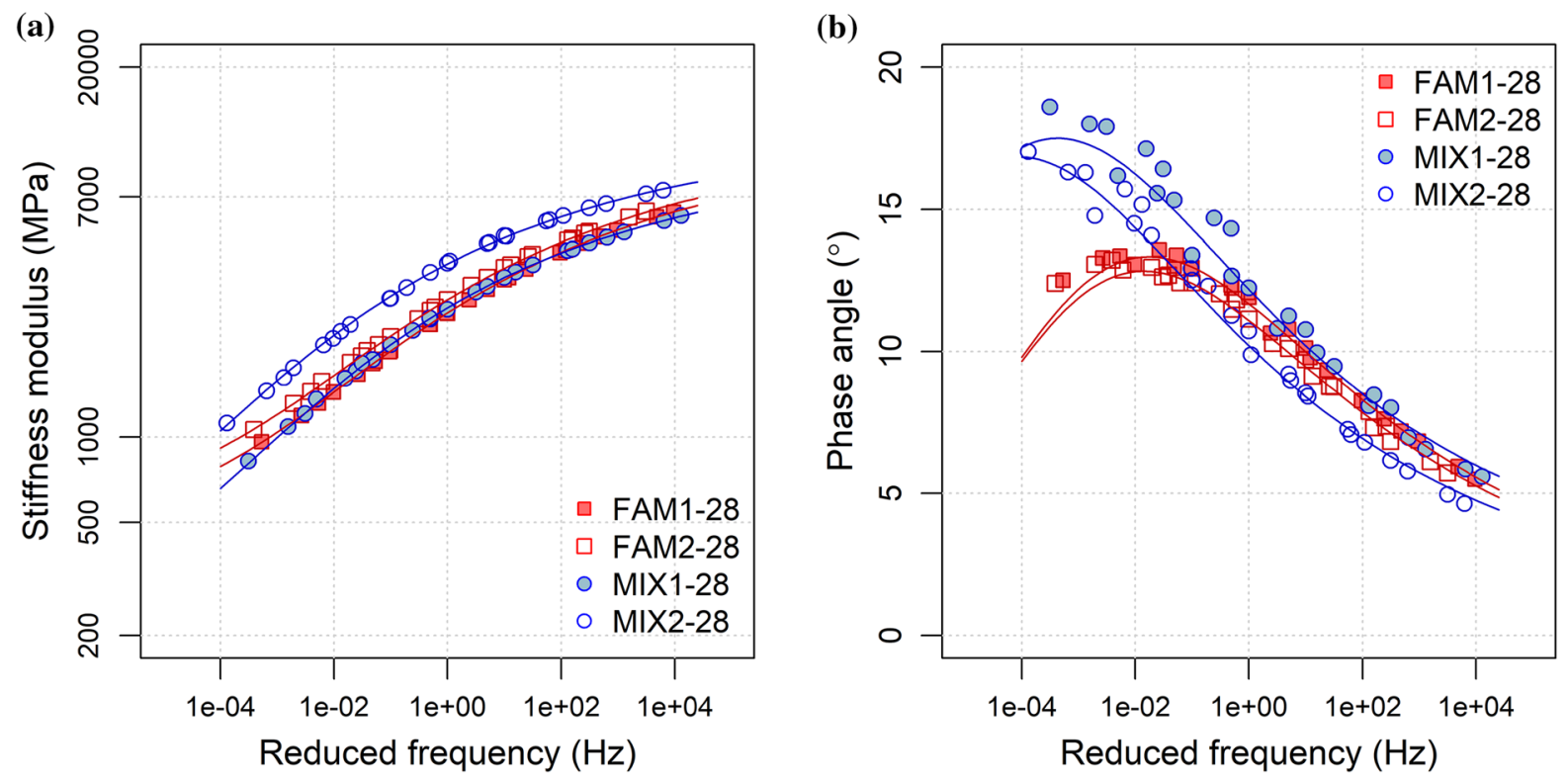

Fig. 10 Master curves after 28 days of curing $\left(T_{\text {ref }}=20^{\circ} \mathrm{C}\right)$, a stiffness modulus, $\mathbf{b}$ phase angle

measured at the other temperatures parallel to the logfrequency axis using Eq. 8:

$f_{\mathrm{r}}=f \cdot a_{T_{\mathrm{ref}}}(T)$

where $f$ is the testing frequency, $f_{\mathrm{r}}$ is the shifted frequency, normally called reduced frequency and $a_{T_{\text {ref }}}(T)$ is the shift factor required to obtain the superposition between the data measured at different temperatures $T$ and at $T_{\text {ref. }}$. The shift factors were calculated using the closed form shifting (CFS) algorithm which is based on the minimization of the area between two adjacent isothermal segments and is operator-independent [42].

The master curves of the phase angle (Fig. 10b) were created applying the same shift factors calculated for the stiffness modulus. As can be observed, the superposition is excellent and confirms that the smallstrain response of the tested mixture and FAM can be considered thermo-rheologically simple.

Figure 11 shows the calculated shift factors as a function of temperature (values of replicate specimens were averaged). The experimental data are modelled with the Williams-Landel-Ferry (WLF) equation [43]:

$\log \left(a_{T_{\text {ref }}}\right)=-\frac{C_{1}\left(T-T_{\text {ref }}\right)}{C_{2}+T-T_{\text {ref }}}$

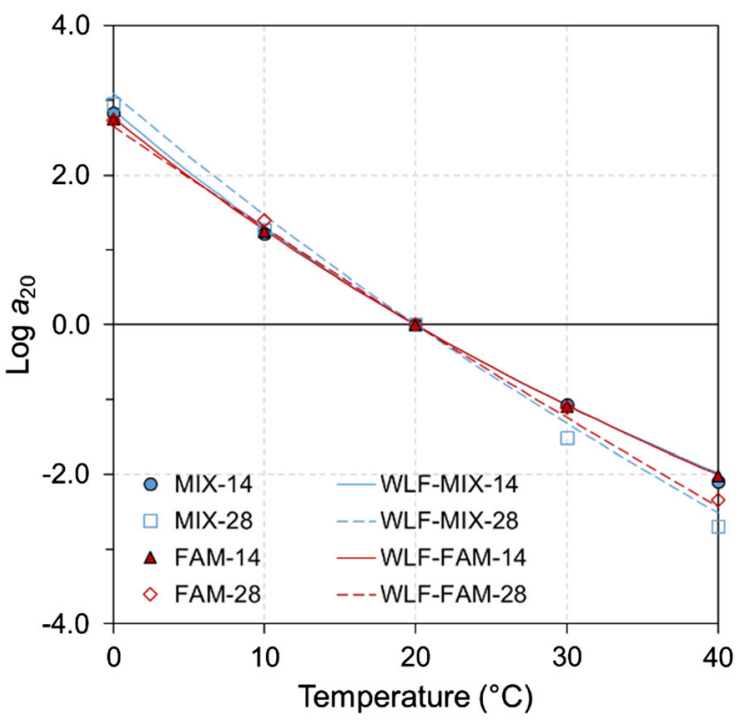

Fig. 11 Shift factors and WLF model

where $C_{1}, C_{2}$ are constants obtained by least squares fitting (Table 2).

The complex modulus data were fitted with a modified version of the Huet-Sayegh (HS) rheological model, described by Eq. 10 [12]:

$E^{*}(\omega)=E_{\mathrm{HS}}^{*}(\omega) \exp \left(\mathrm{j} \delta_{0}\right)$

where $E_{\mathrm{HS}}^{*}(\omega)$ represents the HS model and $\exp \left(\mathrm{j} \delta_{0}\right)$ is 
a correction term which adds a constant (i.e. temperature- and frequency-independent) phase angle $\delta_{0}$. The HS model is described by Eq. 11:

$E_{\mathrm{HS}}^{*}(\omega)=E_{e}+\frac{E_{\mathrm{g}}-E_{\mathrm{e}}}{1+d \cdot(\mathrm{j} \omega \tau)^{-k}+(\mathrm{j} \omega \tau)^{-h}}$

where $\omega=2 \pi f_{\mathrm{r}}$ is the angular frequency $E_{\mathrm{e}}$ and $E_{\mathrm{g}}$ are the equilibrium and glassy values of the stiffness modulus, $d, h$ and $k$ are adimensional parameters controlling the shape of the model and $\tau$ is a characteristic time whose value depends on the selected reference temperature. Table 2 summarizes the estimated model parameters and Fig. 10 shows the fitted model superposed to the experimental data. In Fig. 12 the new model and the HS model are graphically compared using the Cole-Cole and Black diagrams.

CRM mixtures show a frequency- and temperaturedependent behavior that can be attributed to the bituminous component, comprising both the emulsion residue and the aged RAP bitumen. This behavior is analogous to that of HMA and can be simulated using Eq. 11. Specifically, the parameters $0<k<h<1$ represent the order of derivation of two fractional derivative elements (FDE), also called parabolic dashpots. From a physical point of view, $k$ translates the linear viscoelastic (LVE) behavior in the lowtemperature (high-frequency) range, whereas $h$ translates the LVE behavior in the high-temperature (lowfrequency) range [18]. Their lower limit is 0 , representing purely elastic behavior (the FDE becomes a Hookean spring), whereas their upper limit is 1 , representing purely viscous behavior (the FDE becomes a Newtonian dashpot).

Along with viscous damping, Eq. 10 also considers an additional frequency- and temperature-independent damping, represented by the constant phase angle $\delta_{0}$, which was added to the HS model (Eq. 10 and Fig. 12). This is the well-known hysteretic dissipation mechanism [44], that is used to simulate the dynamic response of many materials, including granular (noncohesive) soils [45] and cement concrete [46]. For CRM mixtures, a small but still measurable hysteretic dissipation may be related to the presence of cementitious bonds or to interparticle friction, possibly due to aggregates not fully coated by the bituminous films formed with emulsion setting.

On the one hand, the proposed Eq. 10 is limited because it is applicable only in the frequency domain. On the other hand it is mathematically simple and can be easily extended by replacing the HS model with other LVE models like, for example, the 2S2P1D or the Havriliak-Negami models [47], which are currently used to simulate the behavior of HMA materials.

\subsection{Comparison between mixture and FAM}

First, we highlight that the same values of $k(0.122)$ and $h(0.314)$, along with a slightly variable value of $d$
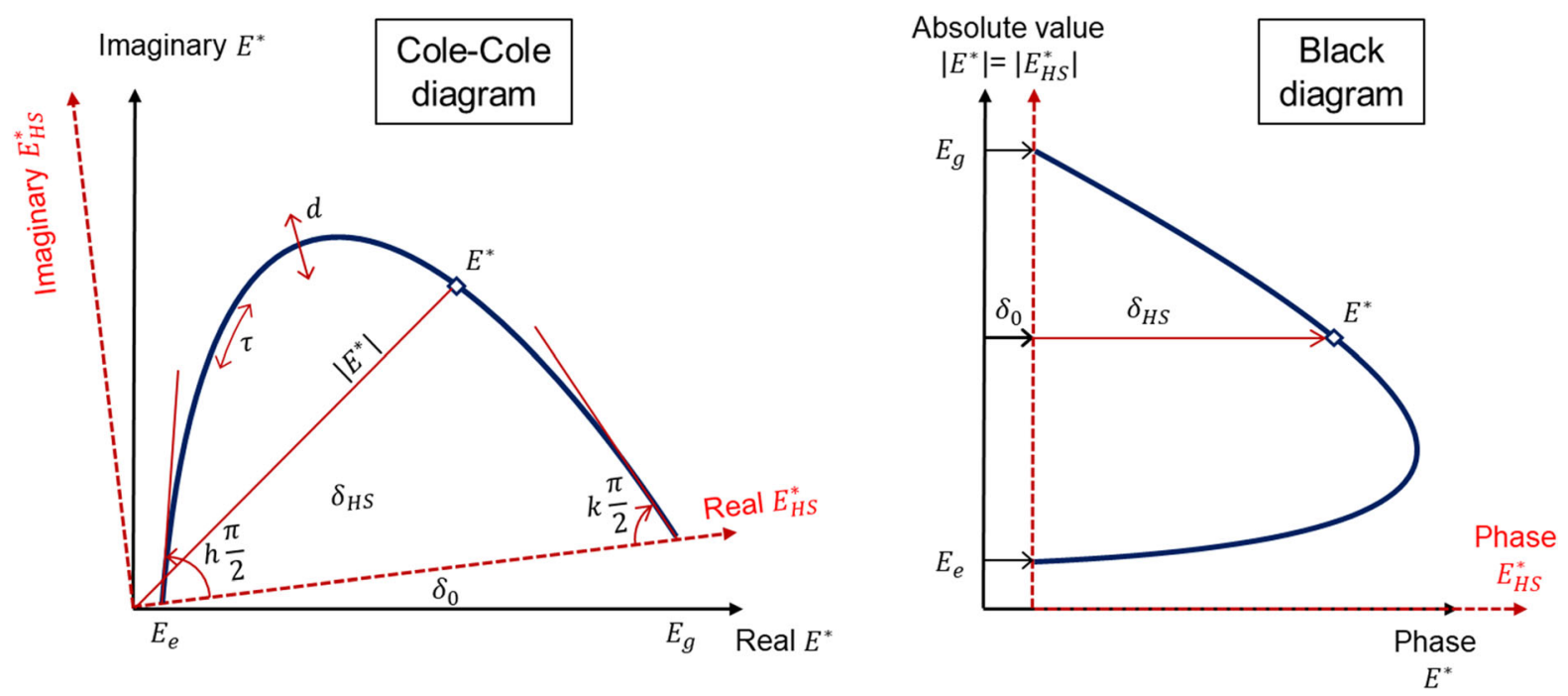

Fig. 12 Comparison between the new model and the HS model 
(1.634-2.000), could be used to simulate the behavior of all the mixture and FAM mortar specimens, at both curing conditions (Table 2). This means that the LVE behavior of the mixture was due to its FAM, which is reasonable since the FAM contained most of the bitumen of the mixture. In fact, only the aged bitumen film coating the coarse RA aggregates was not comprised in the FAM and it clearly played a minor role.

For HMA mixtures, the values of $k$ and $h$ normally range between 0.15 and 0.18 and between 0.44 and 0.70 , respectively $[19,48-50]$. The values obtained in the present research, as well as those reported in other studies on CRM mixtures, are clearly lower [12, 21]. From the model point of view, this indicates that the two parabolic dashpots of the model are closer to a Hookean spring. In other terms, the rheological behavior of CRM mixtures and FAM mortars was characterized by a less marked viscous component with respect to HMA. This suggests that the aged RA bitumen and the fresh bitumen from the emulsion jointly affected the LVE behavior.

Curing did not affect $k$ and $h$, while $d$ had only a small variation from 14 to 28 days. However, we observed (Fig. 8) that the effect of curing is similar to that of frequency and temperature and therefore it should be visible mainly in the parameter $\tau$, which is a frequency multiplier (Eq. 11). In fact, for all tested specimens, the curing time increase led to an increase in $\tau$. This is particularly evident for the two mixture specimens, where the variation is about one order of magnitude (Table 2). From a physical point of view, higher values of $\tau$ characterize materials which are harder and have lower relaxation ability. The corresponding increase in stiffness modulus and the phase angle reduction has been already highlighted in Fig. 9. An increase in $\tau$ was also observed when the fraction of RAP-extracted binder was increased in blends of RAP-extracted binder with virgin binder [51, 52]. This suggests that the longer curing period (14 days at $40{ }^{\circ} \mathrm{C}$ ) caused some aging of the bituminous binder films that formed upon emulsion breaking and setting.

As regards the phase angle $\delta_{0}$, describing the frequency- and temperature-independent dissipation, the mixtures showed values from $1.789^{\circ}$ to $0.945^{\circ}$, which are similar to those obtained for CRM mixtures tested 8 years after construction [12]. The $\delta_{0}$ values were actually very small, but this is not surprising and simply indicates that, for the given composition, the thermo-viscoelastic dissipation due to the bituminous component certainly prevailed (i.e. the material showed an asphalt-like behavior). For FAM mortars $\delta_{0}$ was even smaller, suggesting that the addition of coarse aggregate and voids was responsible for most of the frequency- and temperature-independent dissipation.

The FAM mortar specimens had higher values of the equilibrium modulus, with respect to mixtures; as regards the glassy modulus the two materials showed similar values. For HMA mixtures, $E_{\mathrm{e}}$ and $E_{\mathrm{g}}$ are associated to the contribution of the aggregate skeleton and the air voids content $[53,54]$. From our results, following this interpretation, we may conclude that the reinforcing effect of the coarse RA aggregate was almost perfectly balanced by the presence of the independent voids phase. However, in the hightemperature/low-frequency range $\left(\log f_{\mathrm{r}} \rightarrow-\infty\right)$ we need to be very careful. In that range the bitumen contribution (fresh and aged) to the stiffness becomes negligible, but CRM mixture and mortars also contain cementitious bonds, whose effect probably determine the value of $E_{\mathrm{e}}$.

The rheological behavior of mixture and FAM was also compared using normalized complex modulus curves [53]. We applied the normalization only to the LVE part of the behavior $\left(E^{*} \exp \left(-\mathrm{j} \delta_{0}\right)\right)$ :

$E_{\text {nor }}^{*}=\frac{E^{*} \exp \left(-\mathrm{j} \delta_{0}\right)-E_{\mathrm{e}}}{E_{\mathrm{g}}-E_{\mathrm{e}}}$

Using this definition, we can compare the LVE behavior of mixture and FAM without the influence of $E_{\mathrm{e}}, E_{\mathrm{g}}$ and $\delta_{0}$. In Fig. 13 normalized models are superposed to normalized measured data and the superposition between mixture and FAM is very good. The small effect of curing (difference between 14 and 28 days) is highlighted as a small increase in both $d$ and $\tau$.

\section{Conclusions}

The objective of this study was to compare the rheological behavior of CRM mixtures and FAM mortars. We monitored the curing process by measuring the water loss by evaporation, ITS and ITSM, and performed complex modulus tests at 14 and 28 days of 

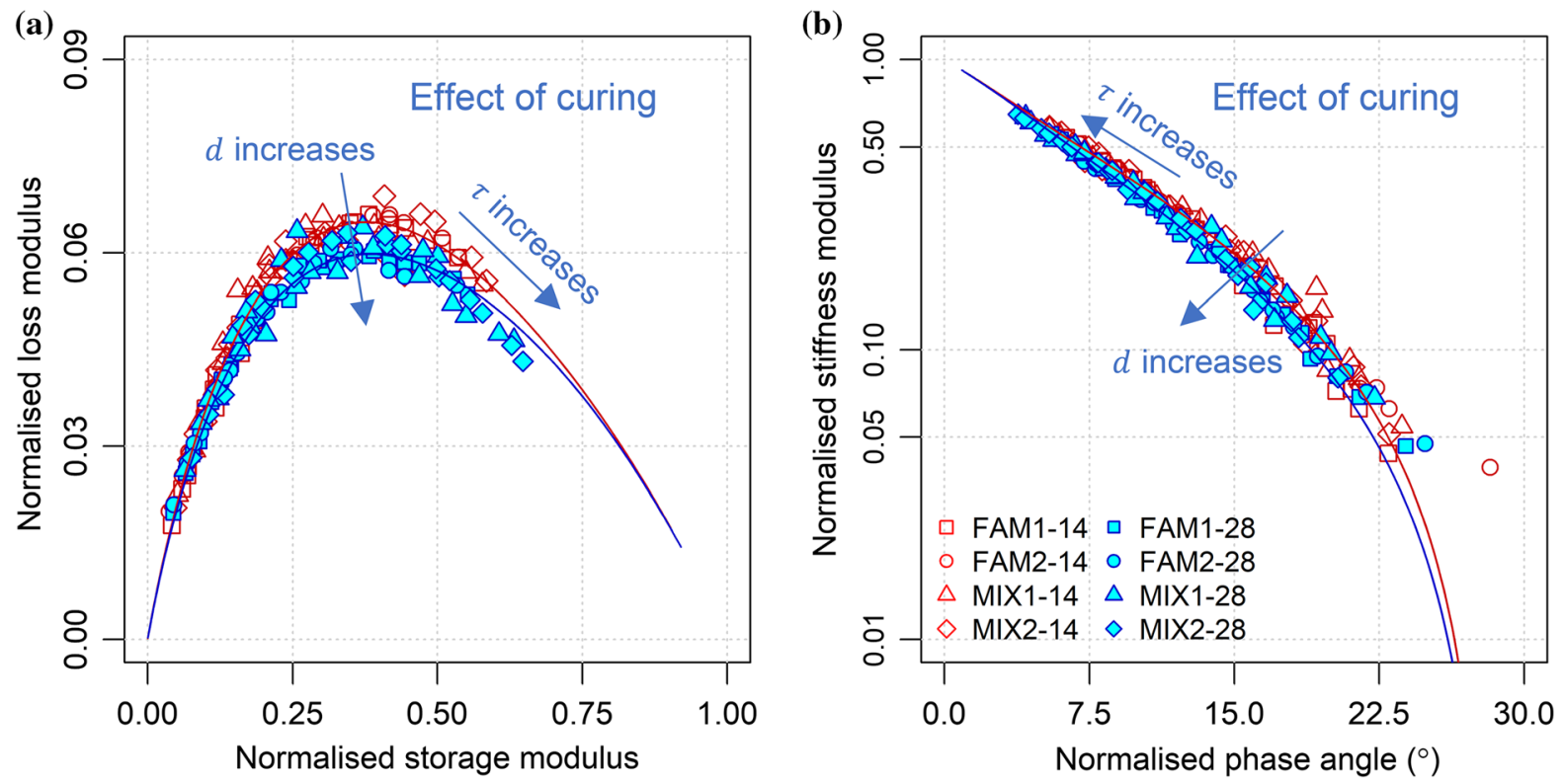

Fig. 13 Comparison between mixture and FAM a normalized Cole-Cole diagram, b normalized Black diagram

curing. Based on the experimental results and analysis, our conclusions are as follows:

- The mixture and the FAM mortar had the same rate of water loss, and their stiffness evolution was strictly linked. In the first curing days the mixture was stiffer, but ultimately the FAM became stiffer. We used the Hirsch model to simulate this behavior and found that the series arrangement of FAM and coarse RA aggregate prevailed on the parallel arrangement.

- The complex modulus results showed that, despite the huge difference in volumetric composition, the thermo-rheological behavior of mixture and FAM mortar was very similar. The effect of curing (increase in stiffness modulus, decrease in phase angle) was similar to that of frequency and temperature. This could be due to aging phenomena that are starting to occur within the bituminous binder films formed upon emulsion setting.

- The rheological behavior of mixtures and FAM mortars was characterized by the presence of a small time- and temperature-independent dissipation component. Therefore, the complex modulus results could be successfully simulated with a new model which, besides viscous dissipation, considers a hysteretic dissipation component. The latter may be related to the presence of cementitious bonds or to interparticle friction, possibly due to aggregates not fully coated by the bituminous films formed upon emulsion setting.

- The new model showed that, similar to HMA mixtures, the rheological behavior of the CRM mixture was controlled by its FAM. The coarse RA aggregate fraction and the voids mainly affected the asymptotic properties (equilibrium and glassy moduli) and the non-viscous dissipation component.

Author contributions Laboratory testing was performed by SR. Data collection and analysis were performed by SR, CM and AG. The first draft of the manuscript was written by AG and all authors commented on previous versions of the manuscript. All authors read and approved the final manuscript.

\section{Compliance with ethical standards}

Conflict of interest The authors declare that there is no conflict of interest regarding the publication of this article.

Open Access This article is licensed under a Creative Commons Attribution 4.0 International License, which permits use, sharing, adaptation, distribution and reproduction in any medium or format, as long as you give appropriate credit to the original author(s) and the source, provide a link to the Creative Commons licence, and indicate if changes were made. The images or other third party material in this article are included in the article's Creative Commons licence, unless 
indicated otherwise in a credit line to the material. If material is not included in the article's Creative Commons licence and your intended use is not permitted by statutory regulation or exceeds the permitted use, you will need to obtain permission directly from the copyright holder. To view a copy of this licence, visit http://creativecommons.org/licenses/by/4.0/.

\section{References}

1. Giani MI, Dotelli G, Brandini N, Zampori L (2015) Comparative life cycle assessment of asphalt pavements using reclaimed asphalt, warm mix technology and cold in-place recycling. Resour Conserv Recycl. https://doi.org/10.1016/ j.resconrec.2015.08.006

2. Thenoux G, González Á, Dowling R (2007) Energy consumption comparison for different asphalt pavements rehabilitation techniques used in Chile. Resour Conserv Recycl 49(4):325-339. https://doi.org/10.1016/j.resconrec. 2006.02.005

3. Xiao F, Yao S, Wang J, Li X, Amirkhanian S (2018) A literature review on cold recycling technology of asphalt pavement. Constr Build Mater 180:579-604. https://doi. org/10.1016/j.conbuildmat.2018.06.006

4. Bocci E, Graziani A, Bocci M (2020) Cold in-place recycling for a base layer of an Italian high-traffic highway. In: Pasetto M, Partl M, Tebaldi G (eds) Proceedings of the 5th international symposium on Asphalt Pavements \& Environment (APE). ISAP APE 2019. Lecture Notes in Civil Engineering, vol 48. Springer, Cham

5. Bocci M, Canestrari F, Grilli A, Pasquini E, Lioi D (2010) Recycling techniques and environmental issues relating to the widening of an high traffic volume Italian motorway. Int J Pavement Res Technol. https://doi.org/10.6135/ijprt.org. tw/2010.3(4).171

6. Timm DH, Diefenderfer BK, Bowers BF (2018) Cold central plant recycled asphalt pavements in high traffic applications. Transp Res Rec. https://doi.org/10.1177/ 0361198118801347

7. Cox BC, Howard IL, Middleton A (2016) Case study of high-traffic in-place recycling on U.S. highway 49: multiyear performance assessment. J Transp Eng 142(12):05016008. https://doi.org/10.1061/(asce)te.19435436.0000900

8. Stimilli A, Ferrotti G, Graziani A, Canestrari F (2013) Performance evaluation of a cold-recycled mixture containing high percentage of reclaimed asphalt. Road Mater Pavement Des. https://doi.org/10.1080/14680629.2013. 774752

9. Guatimosim FV, Vasconcelos KL, Bernucci LLB, Jenkins KJ (2018) Laboratory and field evaluation of cold recycling mixture with foamed asphalt. Road Mater Pavement Des 19(2):385-399. https://doi.org/10.1080/14680629.2016. 1261726

10. Dolzycki B, Jaczewski M, Szydlowski C (2017) The longterm properties of mineral-cement-emulsion mixtures. Constr Build Mater 156:799-808. https://doi.org/10.1016/j. conbuildmat.2017.09.032

11. Valentin J, Č́žzová Z, Suda J, Batista F, Mollenhauer K, Simnofske D (2016) Stiffness characterization of cold recycled mixtures. Transp Res Proc 14:758-767. https://doi. org/10.1016/j.trpro.2016.05.065

12. Graziani A, Mignini C, Bocci E, Bocci M (2020) Complex modulus testing and rheological modeling of cold-recycled mixtures. J Test Eval 48(1):20180905. https://doi.org/10. 1520/jte20180905

13. Schwartz CW, Diefenderfer BK, Bowers BF (2017) Material properties of cold in-place recycled and full-depth reclamation asphalt concrete. The National Academies Press, Washington

14. Cardone F, Grilli A, Bocci M, Graziani A (2015) Curing and temperature sensitivity of cement-bitumen treated materials. Int J Pavement Eng 16(10):868-880. https://doi.org/10. 1080/10298436.2014.966710

15. Preti F, Gouveia BCS, Rahmanbeiki A, Romeo E, Carter A, Tebaldi G (2019) Application and validation of the cohesion test to characterise reclaimed asphalt pavement. Road Mater Pavement Des. https://doi.org/10.1080/14680629.2019. 1590225

16. Diefenderfer BK, Bowers BF, Schwartz CW, Farzaneh A, Zhang Z (2016) Dynamic modulus of recycled pavement mixtures. Transp Res Rec. https://doi.org/10.3141/2575-03

17. Yan J, Zhu H, Zhang Z, Gao L, Charmot S (2014) The theoretical analysis of the RAP aged asphalt influence on the performance of asphalt emulsion cold recycled mixes. Constr Build Mater 71:444-450. https://doi.org/10.1016/j. conbuildmat.2014.09.002

18. Pronk AC (2005) The Huet-Sayegh model: a simple and excellent rheological model for master curves of asphaltic mixes. In: Asphalt concrete, pp 73-82. https://doi.org/10. 1061/40825(185)8

19. Olard F, Di Benedetto H (2003) General '2S2P1D' model and relation between the linear viscoelastic behaviours of bituminous binders and mixes. Road Mater Pavement Des 4(2):185-224. https://doi.org/10.1080/14680629.2003. 9689946

20. Gandi A, Carter A, Singh D (2017) Rheological behavior of cold recycled asphalt materials with different contents of recycled asphalt pavements. Innov Infrastruct Solut 2(1):1-9. https://doi.org/10.1007/s41062-017-0094-3

21. Godenzoni C, Graziani A, Perraton D (2017) Complex modulus characterisation of cold-recycled mixtures with foamed bitumen and different contents of reclaimed asphalt. Road Mater Pavement Des 18(1):130-150. https://doi.org/ 10.1080/14680629.2016.1142467

22. Underwood BS, Kim YR (2011) Experimental investigation into the multiscale behaviour of asphalt concrete. Int $\mathrm{J}$ Pavement Eng 12(4):357-370. https://doi.org/10.1080/ 10298436.2011.574136

23. Underwood BS, Kim YR (2013) Effect of volumetric factors on the mechanical behavior of asphalt fine aggregate matrix and the relationship to asphalt mixture properties. Constr Build Mater 49:672-681. https://doi.org/10.1016/j. conbuildmat.2013.08.045

24. Sousa P, Kassem E, Masad E, Little D (2013) New design method of fine aggregates mixtures and automated method for analysis of dynamic mechanical characterization data. Constr Build Mater 41:216-223. https://doi.org/10.1016/j. conbuildmat.2012.11.038

25. Neumann J, Simon JW, Mollenhauer K, Reese S (2017) A framework for 3D synthetic mesoscale models of hot mix 
asphalt for the finite element method. Constr Build Mater 148:857-873. https://doi.org/10.1016/j.conbuildmat.2017. 04.033

26. Pichler C, Lackner R, Aigner E (2012) Generalized selfconsistent scheme for upscaling of viscoelastic properties of highly-filled matrix-inclusion composites-application in the context of multiscale modeling of bituminous mixtures. Compos Part B Eng 43(2):457-464. https://doi.org/10. 1016/j.compositesb.2011.05.034

27. Underwood BS, Kim YR (2013) Microstructural investigation of asphalt concrete for performing multiscale experimental studies. Int J Pavement Eng. https://doi.org/ 10.1080/10298436.2012.746689

28. Miljković M, Poulikakos L, Piemontese F, Shakoorioskooie M, Lura P (2019) Mechanical behaviour of bitumen emulsion-cement composites across the structural transition of the co-binder system. Constr Build Mater 215:217-232. https://doi.org/10.1016/j.conbuildmat.2019.04.169

29. Miljković M, Radenberg M (2014) Fracture behaviour of bitumen emulsion mortar mixtures. Constr Build Mater 62:126-134. https://doi.org/10.1016/j.conbuildmat.2014. 03.034

30. Mignini C, Cardone F, Graziani A (2018) Experimental study of bitumen emulsion-cement mortars: mechanical behaviour and relation to mixtures. Mater Struct Constr. https://doi.org/10.1617/s11527-018-1276-y

31. Graziani A, Iafelice C, Raschia S, Perraton D, Carter A (2018) A procedure for characterizing the curing process of cold recycled bitumen emulsion mixtures. Constr Build Mater 173:754-762. https://doi.org/10.1016/j.conbuildmat. 2018.04.091

32. Graziani A, Godenzoni C, Cardone F, Bocci M (2016) Effect of curing on the physical and mechanical properties of cold-recycled bituminous mixtures. Mater Des 95:358-369. https://doi.org/10.1016/j.matdes.2016.01.094

33. European Committee for Standardization (CEN) (2010) EN 12697-10 bituminous mixtures. Test methods. Compactability

34. Raschia S, Perraton D, Graziani A, Carter A (2020) Influence of low production temperatures on compactability and mechanical properties of cold recycled mixtures. Constr Build Mater. https://doi.org/10.1016/j.conbuildmat.2019. 117169

35. Grilli A, Graziani A, Bocci E, Bocci M (2016) Volumetric properties and influence of water content on the compactability of cold recycled mixtures. Mater Struct Constr 49(10):4349-4362. https://doi.org/10.1617/s11527-0160792-x

36. Raschia S, Perraton D, Graziani A, Carter A (2020) Influence of low production temperatures on compactability and mechanical properties of cold recycled mixtures. Constr Build Mater 232:117169. https://doi.org/10.1016/j. conbuildmat.2019.117169

37. Shokri N, Lehmann P, Or D (2009) Characteristics of evaporation from partially wettable porous media. Water Resour Res 45(2):1-12. https://doi.org/10.1029/ 2008WR007185

38. Saadoon T, Gómez-Meijide B, Garcia A (2018) Prediction of water evaporation and stability of cold asphalt mixtures containing different types of cement. Constr Build Mater
186:751-761. https://doi.org/10.1016/j.conbuildmat.2018. 07.218

39. Ahmed S, Jones FR (1990) A review of particulate reinforcement theories for polymer composites. J Mater Sci 25(12):4933-4942. https://doi.org/10.1007/BF00580110

40. Christensen DW, Pellinen T, Bonaquist RF (2003) Hirsch model for estimating the modulus of asphalt concrete. In: Asphalt paving technology: association of asphalt paving technologists-proceedings of the technical sessions

41. Kuchiishi AK, Vasconcelos K, Bariani Bernucci LL (2019) Effect of mixture composition on the mechanical behaviour of cold recycled asphalt mixtures. Int $\mathrm{J}$ Pavement Eng. https://doi.org/10.1080/10298436.2019.1655564

42. Gergesova M, Zupančič B, Saprunov I, Emri I (2011) The closed form t-T-P shifting (CFS) algorithm. J Rheol (N Y N Y) 55(1):1-16. https://doi.org/10.1122/1.3503529

43. Williams ML, Landel RF, Ferry JD (1955) The temperature dependence of relaxation mechanisms in amorphous polymers and other glass-forming liquids. J Am Chem Soc 77:3701-3707

44. Genta G (2009) Vibration dynamics and control. Springer, Boston

45. Ashmawy AK, Salgado R, Guha S, Drnevich VP (1995) Soil damping and its use in dynamic analyses. In: Third international conference on recent advanced geotechnical earthquake engineering and soil dynamics, 1-static dynamics engineering soil parameters construction relations soils

46. Chen X, Huang Y, Chen C, Lu J, Fan X (2017) Experimental study and analytical modeling on hysteresis behavior of plain concrete in uniaxial cyclic tension. Int $\mathrm{J}$ Fatigue. https://doi.org/10.1016/j.ijfatigue.2016.12.002

47. Gudmarsson A, Ryden N, Di Benedetto H, Sauzéat C, Tapsoba N, Birgisson B (2014) Comparing linear viscoelastic properties of asphalt concrete measured by laboratory seismic and tension-compression tests. J Nondestruct Eval 33(4):571-582. https://doi.org/10.1007/s10921-014-0253-9

48. Woldekidan MF, Huurman M, Pronk AC (2012) A modified HS model: numerical applications in modeling the response of bituminous materials. Finite Elem Anal Des 53:37-47. https://doi.org/10.1016/j.finel.2012.01.003

49. Graziani A, Bocci M, Canestrari F (2014) Complex Poisson's ratio of bituminous mixtures: measurement and modeling. Mater Struct 47(7):1131-1148. https://doi.org/ 10.1617/s11527-013-0117-2

50. Chabot A, Chupin O, Deloffre L, Duhamel D (2010) ViscoRoute 2.0 a tool for the simulation of moving load effects on asphalt pavement. Road Mater Pavement Des 11(2):227-250. https://doi.org/10.3166/rmpd.11.227-250

51. Mangiafico S, Di Benedetto H, Sauzéat C, Olard F, Pouget $S$, Planque L (2013) Influence of reclaimed asphalt pavement content on complex modulus of asphalt binder blends and corresponding mixes: experimental results and modelling. Road Mater Pavement Des 14(Suppl 1):132-148. https://doi.org/10.1080/14680629.2013.774751

52. Mangiafico S, Di Benedetto H, Sauzéat C, Olard F, Pouget S, Planque L (2014) New method to obtain viscoelastic properties of bitumen blends from pure and reclaimed asphalt pavement binder constituents. Road Mater Pavement Des 15(2):312-329. https://doi.org/10.1080/ 14680629.2013 .870639 
53. Di Benedetto H, Olard F, Sauzéat C, Delaporte B (2004) Linear viscoelastic behaviour of bituminous materials: from binders to mixes. Road Mater Pavement Des 5(Suppl 1):163-202. https://doi.org/10.1080/14680629.2004.9689992

54. Dongré R et al (2005) Field evaluation of Witczak and Hirsch models for predicting dynamic modulus of hot-mix asphalt. Asphalt Paving Technol Assoc Asphalt Paving Technol Proc Tech Sess 74(202):381-442

Publisher's Note Springer Nature remains neutral with regard to jurisdictional claims in published maps and institutional affiliations. 